\title{
The role of mutational analysis of KIT and PDGFRA in gastrointestinal stromal tumors in a clinical setting
}

\author{
Alessandra Maleddu*, Maria A Pantaleo ${ }^{1,2}$, Margherita Nannini $^{1}$ and Guido Biasco ${ }^{1,2}$
}

\begin{abstract}
Gastrointestinal stromal tumors (GIST) are the most common mesenchymal tumors of the gastrointestinal tract. Most GIST harbor a mutation affecting either the KIT or PDGFRA genes, whereas a small subgroup of tumors is wild type for mutations.

Mutation of tyrosine kinase receptors is a mechanism of drug resistance that can occur either at the beginning of treatment (primary resistance) or during the course of therapy (secondary resistance). In addition, mutational status can predict the response to treatment with tyrosine kinase inhibitors, but the role of mutational status as a prognostic factor remains controversial.

Evidence of a potential role of mutational status as a prognostic factor has emerged over the past decade. The presence of KIT exon 11 insertion/deletion involving either one or both Trp557-Lys558 amino acids correlates with a poorer clinical outcome if compared to patients with tumors wild type for KIT exon 11 mutations. A malignant clinical behavior has also been documented for KIT exon 13 and KIT exon 9 mutant GIST. Patients with GIST harboring a PDGFRA mutation seem to have a better prognosis than the others.

The aim of this paper is to review the clinical significance of tyrosine kinase mutational status.
\end{abstract}

\section{Introduction}

Gastrointestinal stromal tumors (GIST) are rare tumors of the gastrointestinal tract. They arise mostly in the stomach, followed by the small bowel and colon. Less frequently they are found in the rectum, esophagus or in an extra-gastrointestinal location. The biology of GIST has been widely investigated since Hirota et al. [1] demonstrated mutations of the KIT receptor as a pathogenic mechanism of GIST. Other mutations affecting KIT exons 9, 13 and 17 have been demonstrated [2,3]. About $15 \%$ of GIST do not express KIT mutations and of these approximately 5 to $7 \%$ have a mutation affecting the gene encoding for PDGFRA [4]. There is also a small subgroup of GIST, called wild type (WT), which do not harbor either KIT or PDGFRA mutations [5].

KIT and PDGFRA are two trans-membrane receptors that belong to the type III tyrosine kinase family whose natural ligands are stem cell factor (SCF) and platelet-

\footnotetext{
* Correspondence: alessandramaleddu@gmail.com

1"L.\&A.Seragnoli" Department of Hematology and Oncological Sciences, S.

Orsola-Malpighi Hospital, University of Bologna, Italy

Full list of author information is available at the end of the article
}

derived growth factor (PDGF). Both receptors have a similar structure with five immunoglobulin-like domains located on the extracellular side of the receptor, a transmembrane portion and an intracellular part containing two tyrosine kinase domains: one with an adenosine triphosphate (ATP) binding region and the other with a phosphotransferase region (activation loop). Activation of the receptor normally occurs with ligand binding which triggers the receptor dimerization, the autophosphorylation of the tyrosine kinase domain and finally the activation of substrates like PI3K/Akt, Ras/MAPK and JAK/STAT. This promotes cell cycle activation, cell proliferation, and apoptosis inhibition [6,7]. Several gain-of-function mutations of KIT and PDGFRA affecting different exons have been reported $[8,9]$.

The correlation between KIT and PDGFRA mutational status and the response to tyrosine kinase inhibitors and their role in primary and secondary resistance has been widely investigated $[10,11]$.

The aim of this paper is to review the clinical significance of mutational status and its value as a predictive/ prognostic factor in limited and metastatic disease. 


\section{Prognostic value of mutational analysis in localized GIST}

Whenever possible surgery is the best treatment for GIST. Unfortunately, even after radical surgery the fiveyear survival rate is about $54 \%$ and the disease-free survival (DFS) is $45 \%[12,13]$. Tumor size $(\geq 10 \mathrm{~cm})$, mitotic rate $(\geq 5 / 50 \mathrm{HPF})$ and tumor location are known to be independent prognostic factors for shorter DFS in fully resected GIST patients. In 2002 Fletcher et al. developed a risk stratification for primary tumors (National Health Institute -NHI classification), considering tumor size and mitotic count as predictive factors of aggressive behavior [6]. In 2006 Miettinen and Lasota analyzed the follow-up data from more than 1600 fully resected tumors and, on the basis of their results, revised the $\mathrm{NIH}$ classification adding primary tumor location as an important prognostic factor to identify the class of risk for resected primary GIST [7]. According to the latest classification, the risk of recurrence goes from being very low for small tumors $(\leq 2 \mathrm{~cm})$ with low mitotic rate $(\leq 5 / 50 \mathrm{HPF})$ and gastric location, to close to $90 \%$ for large tumors $(>10 \mathrm{~cm})$ with high mitotic rate $(\geq 5 /$ $50 \mathrm{HPF}$ ) and small intestinal location [7]. Due to a wide spectrum of behavior, it is crucial to find further factors that can have a prognostic value in predicting the risk of relapse for fully resected tumors. The importance of the mutational status of KIT and PDGFRA as a prognostic factor remains controversial, although its predictive value on tyrosine kinase inhibitors response is now clearer.

Early evidence of a potential role of mutational status as a prognostic factor appeared in the late nineties, when different groups observed a correlation between KIT exon 11 mutations and a poorer clinical outcome compared to patients with tumors WT for KIT exon 11 mutations. Ernst et al. identified a subgroup of 13 KIT exon 11 mutant tumors in a larger group of 35 GIST patients and observed that the mutation was associated with a shorter survival rate $(\mathrm{p}=0.001)$. No correlation between mutations, tumor size or mitotic index was observed [14]. When GIST were still classified as malignant or benign, KIT exon 11 mutations were noticed to be more common in the malignant subtype [15]. In addition, a study of 124 GIST patients showed a clear difference in prognosis for patients with or without KIT exon 11 mutations and a subdivision into mutationpositive and mutation-negative patients was proposed [16]. However, in 1999 only KIT exon 11 was studied and the prognostic role of mutations could not be evaluated.

Malignant clinical behavior was also documented for KIT exon 9 and KIT exon 13 mutant GIST [16-18], and for the first time the association between KIT exon 9 mutation and small intestinal location was reported [17].
In general, all the cited studies focused on KIT exon 11 mutations, whereas few dealt with KIT exon 9, 13 or 17 mutations. The first study to screen KIT exons 9, 11, 13, and 17 for mutations was performed in 2002 by Singer et al.: 44 tumors out of 48 harbored a KIT mutation. They found a KIT mutation was associated with a poor clinical outcome and they also hypothesized that specific KIT mutations could have a prognostic value. The multivariate analysis showed that patients with GIST harboring a KIT deletion/insertion had a significantly shorter recurrence-free survival (RFS) than patients with tumors harboring a KIT exon 11 missense mutation, which was more common in favorable-outcome, low-grade GIST [19]. A larger study on 120 patients identified two small subgroups with different clinical outcomes [20]. The first small subgroup of eight cases had a more favorable prognosis and consisted of tumors harboring an insertion of 6-20 amino acids representing intra-tandem-duplications (ITDs) at the 3' end of exon 11. All eight tumors were located in the stomach, had a spindle cell morphology, and a low mitotic count. Patients were all older than 60 years of age and seven out of eight were female. The second subgroup included 13 tumors that harbored a KIT exon 9 mutation, had a predominant small intestinal location and a poorer outcome compared to the other patients [18].

In 2005 a large retrospective study by Kim et al. enrolled 86 patients who underwent radical resection of localized GIST [21]. Sixty-one GIST had a mutation of KIT exon 11 and three had a mutation of KIT exon 9. KIT exons 13 and 17 were screened but no mutations were found in 22 tumors. The class of risk considering tumor size and the mitotic rate was identified for all the patients. All three KIT exon 9 mutations were insertions of six nucleotides, resulting in duplication of Ala502Tyr503, two patients had a high risk GIST but all three KIT exon 9 mutants had a relapse of the disease. The most common mutation of KIT exon 11 was a deletion that involved codons between 550 and 570. Three IDTs were also found in tumors with spindle cell morphology, no mitotic activity and benign clinical behaviors. The patients were all female and were all alive and relapsefree after 24-80 months of follow-up, despite the tumor risk class. In general the five-year RFS for patients whose tumor harbored a KIT mutation was significantly shorter than for patients with tumors without KIT mutations. KIT mutations were also observed to be associated with a higher mitotic rate, which together with tumor size was already a known negative prognostic factor [21].

Wardelmann et al. correlated the mutational status of 55 GIST and the clinical outcome. The size of 50 tumors was known, 21 tumors had a diameter $\leq 5 \mathrm{~cm}$ and none of them had evidence of metastasis, 29 tumors 
had a diameter larger than $5 \mathrm{~cm}$ and 15 of them had a metastatic spread. A mutation affecting 557 and/or 558 codons of KIT exon 11 was found in 13 of 15 metastatic tumors and in only two of the nine mutated and not metastatic tumors. These results suggested that mutations involving 557 and/or 558 codons could be used as an additional parameter to estimate poor survival [22]. Subsequent studies confirmed the hypothesis of an association between a KIT exon 11 insertion/deletion involving either one or both Trp557-Lys558 amino acids and a poor clinical outcome [23,24]. DeMatteo et al. studied a series of 127 non-metastatic GIST patients who underwent complete tumor resection and were all entered in a follow-up program [24]. As expected, tumor size, mitotic rate and location predicted the RFS in the multivariate analysis. Only in the univariate analysis did KIT exon 9 mutations and KIT exon 11 deletions involving codons 557 and/or 558 correlate with a higher rate of recurrence, whereas patients with point of mutation or insertion of KIT exon 11 had a lower rate of recurrence, and patients with WT tumors had an intermediate outcome. Only four patients had a GIST harboring a mutation of KIT exon 9, they all had a disease recurrence but the number was too small to hypothesize a prognostic value [24].

The Spanish Group for Sarcoma Research (GEIS) selected 162 patients who underwent complete resection of localized GIST between 1994 and 2001. All the tumors were $\geq 2 \mathrm{~cm}$ and KIT positive at immunohistochemical analysis. They evaluated the prognostic value of RFS prediction of different KIT and PDGFRA mutations. The results were analyzed when the median follow-up was 42 months and at that point 41 of the 162 patients experienced a disease recurrence and the fiveyear RFS was $68 \%$. According to the NIH and the Miettinen-Lasota risk classifications, tumors with a high mitotic count and large dimensions had a significantly shorter RFS. In addition, following the Miettinen-Lasota revised risk classification the RFS was significantly shorter for patients whose primary tumor was located in the small bowel compared to patients whose primary tumor was located in the stomach. A very interesting statistic was the higher recurrence rate (5-year RFS 57\% $\pm 13 \%$ ) of tumors harboring mutations of the KIT gene, rather than tumors without KIT mutations (5-year RFS $80 \% \pm 11 \%)$. In the univariate analysis, patients with deletions involving codons 557 and/or 558 of KIT exon 11 had a less favorable outcome than patients with different mutations or without KIT mutations. The presence of deletions involving codons 557 and/or 558 of KIT exon 11 was also significantly associated with a higher rate of recurrence in the multivariate analysis together with size, mitotic count and high cellularity, which are known prognostic factors [25].
After a longer follow-up, the data from the same group of 162 patients were analyzed again by the Spanish Group for Sarcoma Research (GEIS). The first analysis demonstrated that the mutations within KIT exon 11 involving codons 557 and/or 558 have a prognostic relevance. The objective of the new study was to demonstrate if critical deletions still are an independent prognostic factor after a longer follow-up, and if there were any time-related prognostic factors for RFS. When the analysis was performed the median follow-up was 84 months, the factors assessed were the class of risk (both classifications NIH and Miettinen-Lasota were considered) and the type of mutation. Mutations were also classified as deletions of codons 557 and/or 558 of KIT exon 11 (critical mutations), non-deletion-type mutations of KIT exon 11 (NDTM) which included missense mutations and insertions, and other deletions of KIT exon 11. Results showed that, for the first four years after surgery and for the entire seven-year follow-up the presence of critical deletions belonging to a high-risk category were independent prognostic factors for RFS. In the first 4 years after surgery only the high-risk category of the MiettinenLasota classification and NDTM were independent prognostic factors for RFS. In fact, the presence of critical mutations could be useful to identify a subset of patients with a higher risk of relapse in the first four years after surgery, whereas the presence of NDTM could identify a subset of patients more likely to experience a relapse beyond three or four years after surgery [26].

A better outcome and a lower chance of metastasis seem to be associated with PDGFRA exon 18 mutations [27]. Lasota et al. screened 1000 GIST for KIT exon 11 mutations, KIT exon 9 (only the non-gastric tumors) and PDGFRA exons 18 and 12. PDGFRA mutant tumors had a prevalent gastric location, epithelioid morphology (pure or prevalent) and low mitotic count. Of 1000 GIST, a PDGFRA exon 18 mutation was found in 122 of the 346 gastric tumors and only two of the 75 small intestinal tumors. Ten of the 170 gastric tumors and one of the 54 small intestinal tumors had a PDGFRA exon 12 mutation. One hundred and five of those had $\leq 5$ mitosis/50HPF, and 40 had no mitotic activity. Clinical data were available for 91 out of 128 PDGFRA exon 18 mutant tumors. After a median follow-up of 135 months, 41 were alive and with no evidence of disease, 24 had died from other causes, 16 had died for unknown causes, and ten had a progressive disease. Seven died of the disease and three were still alive at the end of the follow-up (370 months). The authors concluded that $83 \%$ of GIST with PDGFRA mutations have a good prognosis [27]. The same group of scientists demonstrated later that PDGFRA exon 14 mutant GIST are mostly gastric, have epithelioid morphology and benign clinical behavior [28]. 


\section{Predictive value of response to therapy}

Although the role of KIT/PDGFRA mutational status as a prognostic factor is controversial, it is well known to predict the response to treatment with tyrosine kinase inhibitors.

The mutation of tyrosine kinase receptors is a mechanism of drug resistance occurring either at the beginning of treatment (primary resistance) or during the course of therapy (secondary resistance).

The first study that showed the correlation between the response to imatinib at a dose of $400 \mathrm{mg} /$ day and mutational status in GIST was performed by Heinrich et al. One hundred and twenty-seven patients with metastatic GIST received imatinib, 71 had a tumor with a mutation of KIT exon 11, 23 of KIT exon 9, two of KIT exon 13 and KIT exon 17; PDGFRA exon 18 was mutated in six cases and nine tumors were WT. The clinical response varied considering the different mutations, the stronger predictor of response being any KIT exon 11 mutation. The $87.5 \%$ of patients whose tumor had a KIT exon 11 mutation achieved a partial response, whereas only $47.8 \%$ of patients whose tumor had a KIT exon 9 mutation had a partial response [10].

The European Organization for Research and Treatment of Cancer (EORTC) phase I and II studies [29-31] enrolled patients with metastatic GIST and tested the safety of imatinib given at a dose of $400 \mathrm{mg} /$ day or 800 $\mathrm{mg} /$ day and investigated its activity. The results of the mutational analysis performed on 37 tumor specimens showed a further correlation between certain mutations and their response to imatinib. Of the 37 tumors, 24 had a KIT exon 11 mutation, four had a KIT exon 9 mutation, one had a KIT exon 13 mutation and two had a PDGFRA exon 18 mutation. Patients whose tumors had a KIT exon 11 mutation had a higher partial response rate than the others and patients whose tumors harbored a KIT mutation enjoyed a longer median survival time and a lower recurrence rate [32].

Two recent randomized phase III studies compared the outcome of metastatic GIST patients treated with imatinib $400 \mathrm{mg} /$ day or $800 \mathrm{mg} /$ day. The EU-AUS trial (EORTC and Australian Gastro-Intestinal Trial Group) enrolled 946 patients with metastatic GIST between 2001 and 2002. The primary endpoint of the study was RFS and the patients were randomized to receive imatinib at the two doses with the possibility of cross over to the higher doses in case of progressive disease [33]. Mutational analysis was performed in 377 cases: 248 harbored a KIT exon 11 mutation, 58 a KIT exon 9 mutation, six a KIT exon 13 mutation, and three a KIT exon 17 mutation, whereas ten tumors harbored a PDGFRA exon 18 mutation. Patients with tumors expressing any mutation of KIT exon 11 had a higher response rate and a longer median survival than patients whose tumors harbored KIT exon 9 mutations or whose tumors were WT. Once the KIT exon 11 tumor mutant group was divided into subgroups, the statistical analysis revealed a poorer outcome for patients whose tumor had large exon 11 deletions, especially if involving codons 577-579, this may be due to the conformational change in the receptor. In the group of KIT exon 9 mutant tumors the response rate was significantly higher for patients enrolled in the $800 \mathrm{mg} /$ day arm [33].

The other phase III study (US-CDN) was conducted by the Southwest Oncology Group (SWOG), Cancer and Leukemia Group B (CALGB), National Cancer Institute of Canada (NCI-C) and Eastern Cooperative Oncology Group (ECOG) [34]. This study, which had OS as primary endpoint, enrolled 746 patients with advanced GIST and randomized them to receive imatinib $400 \mathrm{mg} /$ day or $800 \mathrm{mg} /$ day equal to the EU-AUS trial. Of the total, 428 tumors were screened for KIT and PDGFRA mutations. The analysis disclosed a KIT exon 11 mutation in 283 cases, a KIT exon 9 mutation in 32 cases, whereas 67 tumors were WT. Patients were randomly assigned to receive imatinib at the daily dose of $400 \mathrm{mg}$ or $800 \mathrm{mg}$. The time to progression (TTP) did not change for patients with any KIT exon 11 mutation or WT GIST. Patients with a KIT exon 9 mutation had a significantly higher rate of response if treated with imatinib at the daily dose of $800 \mathrm{mg}$, but there was no difference in time to progression and overall survival between the two groups. No differences were observed for KIT exon 11 mutant or WT GIST treated with 400 or $800 \mathrm{mg} /$ day. Instead, any KIT exon 11 mutation was associated with a better outcome in patients with advanced GIST treated with imatinib compared to patients with KIT exon 9 mutations or WT tumors [34].

The Gastrointestinal Stromal Tumor Meta-Analysis Group (MetaGIST) re-analyzed and compared the data from the EU-AUS and the US-CDN studies to confirm the results, validate the suggested prognostic and predictive factors and to explain the differences between results in the two studies by reviewing the characteristics of the two populations.

A small advantage on PFS was observed for the highdose arm in both studies, no difference in overall survival (OS). Prognostic factors for PFS and OS were then considered. Mutational status was a significant prognostic factor $(\mathrm{p}<0.0001)$ for PFS, and patients with KIT exon 11 mutation had a more favorable prognosis than those with exon 9 mutation or WT.

Exon 9 mutation was the only significant predictive factor for a benefit of high-dose therapy. Patients with KIT exon 9 mutations treated with imatinib $800 \mathrm{mg} /$ day had a significantly longer PFS than the others and the 
estimated rate of progression or death was also significantly decreased $(\mathrm{p}=0.017)$ [35].

A further phase III trial compared two doses of imatinib for treatment of unresectable advanced GIST. To investigate the influence of mutational status on imatinib response, 128 GIST specimens from those patients were screened for KIT and PDGFRA mutations. The estimated median survival was 63 months for patients whose tumor harbored a KIT exon 11 mutation, 44 months for patients whose tumors harbored a KIT exon 9 mutation and 26 months in case of other mutations or WT GIST. In addition, a mutation within KIT exon 11 was associated with a better outcome for the first 30 months of therapy [36].

Fewer studies have defined the role of mutational status as a prognostic and predictive factor in the adjuvant setting. It is well known that adjuvant therapy with imatinib is associated with a longer RFS [37]. For this purpose 713 patients who underwent complete resection of a primary GIST were enrolled on the Z9001 study. All primary tumors were $\geq 3 \mathrm{~cm}$ and expressed KIT. Patients were randomized to receive imatinib $400 \mathrm{mg} /$ day for one year or a placebo. Tumor size, mitotic index and mutational status were available for 513 patients. After a median follow-up of 20 months, the two-year RFS was $74 \%$ in the placebo arm vs. $91 \%$ in the imatinib arm. The two-year RFS for patients with KIT exon 11 mutation was $65 \%$ vs. $91 \%$ (placebo and imatinib arm respectively $\mathrm{p}<0.0001), 76 \%$ vs. $100 \%$ for the PDGFRA mutation $(\mathrm{p}<0.01)$, whereas there were no difference in overall RFS for KIT exon 9 mutation, but the one-year RFS was shorter for patients in the placebo arm (80\%) than in the imatinib arm (100\%). This study showed that mutational status together with pathological features have a prognostic and predictive value for RFS after complete surgical resection of primary GIST [38].

Secondary resistance occurs after a median period of 24 months of treatment with imatinib. There are several mechanisms involved in resistance like the activation of an alternative downstream signaling pathway such as $\mathrm{AKT} / \mathrm{mTOR}$, the activation of an alternate tyrosine kinase receptor and the loss of KIT expression, the genomic amplification of KIT, and the gain of new KIT/ PDGFRA mutations [39]. New KIT/PDGFRA mutations are currently considered the most important and the most common mechanism [40-43].

Mutational analysis performed on tissue specimens from resistant lesions disclosed secondary acquired mutations developed during imatinib therapy. The frequency of secondary mutations is over $50 \%$ in those tumors with primary KIT exon 9 or 11 mutations. Secondary mutations are single substitutions and occur in different exons but on the same allele of the primary mutation. Similar to chronic myeloid leukemia, acquired imatinib resistant mutations affect the tyrosine kinase domain and the activation loop, encoded by exons 13 , 14 and 17 respectively $[9,40,43-47]$. The most common secondary mutation is the $\mathrm{V} 654 \mathrm{~A}$, mainly found in GIST harboring an exon 11 primary mutation [48]. PDGFRA secondary mutations are rare. The D842V was identified in one patient with primary mutation V561D, which is known to be associated with imatinib resistance [48]. In general, secondary mutations were detected only in progressive nodules and not in non-progressive ones $[46,49]$. In addition, patients with WT GIST do not develop secondary mutations [46]. A recent study by Liegl et al. analyzed 53 metastases from 14 patients after imatinib or sunitinib treatment failure. Primary tumors included GIST with classical features (KIT positive, and mutated on KIT exons 9, 11, or 13), but also KIT negative tumors, GIST with unusual morphology, and KIT/ PDGFRA WT GIST. Secondary KIT mutations were found in nine out of 11 GIST with KIT primary mutation. Two to five different mutations were found in different metastases I six out of nine patients, and in three out of nine patients two mutations were found in one or more tumor samples. Five recurrent points of mutation were located in the KIT tyrosine kinase domain and in the ATP activation loop. No secondary mutations were found in KIT/PDGFRA WT GIST or in those with unusual morphology [47].

Sunitinib inhibits double mutant GIST and the response to therapy is influenced by the mutational status $[11,50]$. Seventy-eight imatinib resistant patients were treated with sunitinib, $58 \%$ of patients had tumors harboring KIT exon 9 mutations, 34\% had tumors harboring KIT exon 11 mutations, and 56\% of tumors were WT. Results showed a significantly longer progression-free survival and overall survival for patients with primary KIT exon 9 mutations $(\mathrm{p}<0.0005)$ or WT $(\mathrm{p}<0.0356)$ than for those with KIT exon 11 mutations. In addition, patients whose tumor expressed a secondary mutation affecting exons 13 or 14 had a better outcome than those whose tumor had a KIT exon 17 or 18 mutation [11].

In addition to the cellular and mutational profile of the disease, broad variations of imatinib plasma levels have been monitored in GIST patients [51,52]. The decrease of imatinib bioavailability during chronic therapies should be considered a further possible mechanism of resistance. Recently Demetri et al. studied the imatinib pharmacokinetic and pharmacodynamic profiles in advanced GIST patients to detect possible correlations between the imatinib plasma concentrations and clinical outcome. They observed that patients with the lowest imatinib serum levels had the lowest overall response rate and the shortest time to progression [51,52]. 


\section{Conclusions}

The value of mutational status as a predictive and prognostic factor for RFS in metastatic GIST treated with imatinib is clear. What is now becoming more evident is its potential role as a predictive and prognostic factor for resected GIST treated with imatinib. Tumors harboring KIT exon 11 mutations have a better outcome under imatinib treatment at a dose of $400 \mathrm{mg} /$ day than tumors harboring different mutations, and KIT exon 9 mutant tumors have a longer RFS if treated with the high dose of imatinib, corresponding to $800 \mathrm{mg} /$ day. Patients with KIT exon 9 mutant tumors achieve a better response to sunitinib, than those with exon 11 mutations. The PDGFRA exon 18 D $842 \mathrm{~V}$ point mutant activates PDGFRA both in vitro and in vivo $[10,50]$ and is also imatinib resistant in vivo and in vitro [30,53,54], whereas other mutations affecting exon 18 (D846Y, N848K, Y849K and HDSN845-848P) are imatinib sensitive [53].

In the adjuvant setting, available data show that mutational status can be considered a predictive and prognostic factor for GIST patients treated with imatinib after radical surgery [38].

Dei Tos et al. recently reviewed a series of 929 untreated GIST to correlate the natural history of disease with pathological features, but the mutational status of tumors was not available [55]. Tumor size $(\geq 10 \mathrm{~cm})$, mitotic rate $(\geq 5 / 50 \mathrm{HPF})$ and tumor location are the only recognized independent prognostic factors for GIST patients [11,12], but unfortunately it is still unclear whether or not mutational status could be an independent prognostic factor for disease recurrence in untreated patients. It would be useful to be able to study mutational status on a large population of untreated GIST but this has become more difficult since evidence emerged of a longer RFS following adjuvant treatment with imatinib.

Lastly, knowledge of the predictive and prognostic value of mutational status could lead physicians to establish the dose of imatinib, identify those patients who would not benefit from imatinib treatment (PDGFRA exon 18 D842V mutant tumors are imatinib resistant), chose a second line therapy, and evaluate the different risk of relapse during follow-up. These data emphasize that mutational status must play a predominant role in the clinical management of patients and that new findings are necessary to establish the mechanisms responsible for imatinib resistance in specific subsets of tumors like PDGFRA D842V mutant and WT GIST.

\section{Abbreviations}

WT: Wild Type; ATP: Adenosine Triphosphate; PDGFRA: Platelet Derived Growth Factor Receptor Alpha; TKI: Tyrosine Kinase Inhibitor; DFS: Disease Free Survival; NHI: National Health Institute; HPF: High Power Field; ITDs:
Intra-Tandem-Duplications; RFS: Recurrence-Free Survival; NDTM: NonDeletion-Type-Mutations; OS: Overall Survival; PFS: Progression-Free Survival.

\section{Author details}

1"L.\&A.Seragnoli" Department of Hematology and Oncological Sciences, S. Orsola-Malpighi Hospital, University of Bologna, Italy. ${ }^{2 " G}$. Prodi" Interdepartmental Centre of Cancer Research, University of Bologna, Italy.

\section{Authors' contributions}

AM designed the study, carried out the acquisition and participated in data interpretation. GB participated in data interpretation and manuscript revision. MN participated in the acquisition and interpretation of the data. MAP conceived the study, helped to draft the manuscript and interpret the data. All authors read and approved the final manuscript.

\section{Competing interests}

The authors declare that they have no competing interests.

Received: 14 December 2010 Accepted: 23 May 2011

Published: 23 May 2011

\section{References}

1. Hirota S, Isozaki K, Moriyama Y, Hashimoto K, Nishida T, Ishiguro S, Kawano K, Hanada M, Kurata A, Takeda M, Muhammad Tunio G, Matsuzawa $Y$, Kanakura $Y$, Shinomura $Y$, Kitamura $Y$ : Gain of function mutations of c-kit in human gastrointestinal stromal tumors. Science 1998, 279:577-580

2. Lux ML, Rubin BP, Biase TL, Chen CJ, Maclure T, Demetri G, Xiao S, Singer S, Fletcher CD, Fletcher JA: KIT extracellular and kinase domain mutations in gastrointestinal stromal tumors. Am J Pathol 2000, 156:791-795.

3. Rubin BP, Singer $S$, Tsao C, Duensing A, Lux ML, Ruiz R, Hibbard MK, Chen CJ, Xiao S, Tuveson DA, Demetri GD, Fletcher CD, Fletcher JA: KIT activation is a ubiquitous feature of gastrointestinal stromal tumors. Cancer Research 2001, 61:8118-8121.

4. Heinrich MC, Corless CL, Duensing A, McGreevey L, Chen CJ, Joseph N, Singer S, Griffith DJ, Haley A, Town A, Demetri GD, Fletcher CD, Fletcher JA: PDGFRA activating mutations in gastrointestinal stromal tumors. Science 2003, 299:708-710.

5. Medeiros F, Corless CL, Duensing A, Hornick $J$, Oliveira AM, Heinrich MC, Fletcher JA, Fletcher CD: KIT-negative gastrointestinal stromal tumors. Am J Surg Pathol 2004, 28:889-894.

6. Fletcher CD, Berman JJ, Corless C, Gorstein F, Lasota J, Longley BJ, Miettinen M, O'Leary TJ, Remotti H, Rubin BP, Shmookler B, Sobin LH, Weiss SW: Diagnosis of gastrointestinal stromal tumors: A consensus approach. Hum Pathol 2002, 33:459-465.

7. Miettinen $M$, Lasota J: Gastrointestinal stromal tumors: review on morphology, molecular pathology, prognosis, and differential diagnosis. Arch Pathol Lab Med 2006, 130:1466-1478.

8. Lasota J, Miettinen M: Clinical significance of oncogenic KIT and PDGFRA mutations in gastrointestinal stromal tumours. Histopathology 2008, 53:245-266.

9. Corless CL, Fletcher JA, Heinrich MC: Biology of Gastrointestinal Stromal Tumors. J Clin Oncol 2004, 22:3813-3825.

10. Heinrich $M C$, Corless $C L$, Demetri $G D$, Blanke CD, von Mehren $M$, Joensuu H, McGreevey LS, Chen CJ, Van den Abbeele AD, Druker BJ, Kiese B, Eisenberg B, Roberts PJ, Singer S, Fletcher CD, Silberman S, Dimitrijevic $S$, Fletcher JA: Kinase mutations and imatinib response in patients with metastatic gastrointestinal stromal tumors. J Clin Oncol 2003, 21:4342-4349.

11. Heinrich MC, Maki RG, Corless CL, Antonescu CR, Harlow A, Griffith D, Town A, McKinley A, Ou WB, Fletcher JA, Fletcher CD, Huang X, Cohen DP, Baum CM, Demetri GD: Primary and Secondary Kinase Genotypes Correlate With the Biological and Clinical Activity of Sunitinib in Imatinib-Resistant Gastrointestinal Stromal Tumor. J Clin Oncol 2008, 33:5352-5359.

12. Gold JS, Gönen M, Gutiérrez A, Broto JM, García-del-Muro X, Smyrk TC, Maki RG, Singer S, Brennan MF, Antonescu CR, Donohue JH, DeMatteo RP: Development and validation of a prognostic nomogram for recurrencefree survival after complete surgical resection of localised primary gastrointestinal stromal tumour: a retrospective analysis. Lancet Oncol 2009, 10:1045-1052. 
13. DeMatteo RP, Lewis JJ, Leung D, Mudan SS, Woodruff JM, Brennan MF: Two hundred gastrointestinal stromal tumors: recurrence patterns and prognostic factors for survival. Ann Surg 2000, 231:51-58.

14. Ernst SI, Hubbs AE, Przygodzki RM, Emory TS, Sobin LH, O'Leary TJ: KIT mutation portends poor prognosis in gastrointestinal stromal/smooth muscle tumors. Lab Invest 1998, 78:1633-1636.

15. Lasota J, Jasinski M, Sarlomo-Rikala M, Miettinen M: Mutations in exon 11 of c-Kit occur preferentially in malignant versus benign gastrointestinal stromal tumors and do not occur in leiomyomas or leiomyosarcomas. Am J Pathol 1999, 154:53-60.

16. Taniguchi M, Nishida T, Hirota S, Isozaki K, Ito T, Nomura T, Matsuda H, Kitamura Y: Effect of c-kit mutation on prognosis of gastrointestinal stromal tumors. Cancer Res 1999, 59:4297-4300.

17. Lasota J, Wozniak A, Sarlomo-Rikala M, Rys J, Kordek R, Nassar A, Sobin LH, Miettinen M: Mutations in exons 9 and 13 of KIT gene are rare events in gastrointestinal stromal tumors. A study of 200 cases. Am J Pathol 2000, 157:1091-1095

18. Sakurai S, Oguni S, Hironaka M, Fukayama M, Morinaga S, Saito K: Mutations in c-kit gene exons 9 and 13 in gastrointestinal stromal tumors among Japanese. Jpn J Cancer Res 2001, 92:494-498.

19. Singer $S$, Rubin $B P$, Lux ML, Chen CJ, Demetri GD, Fletcher CD, Fletcher JA: Prognostic value of KIT mutation type, mitotic activity, and histologic subtype in gastrointestinal stromal tumors. J Clin Oncol 2002, 20:3898-3905.

20. Antonescu CR, Sommer G, Sarran L, Tschernyavsky SJ, Riedel E, Woodruff JM, Robson M, Maki R, Brennan MF, Ladanyi M, DeMatteo RP, Besmer P: Association of KIT exon 9 mutations with nongastric primary site and aggressive behavior: KIT mutation analysis and clinical correlates of 120 gastrointestinal stromal tumors. Clin Cancer Res 2003, 9:3329-3337.

21. Kim TW, Lee H, Kang YK, Choe MS, Ryu MH, Chang HM, Kim JS, Yook JH, Kim BS, Lee JS: Prognostic significance of c-kit mutation in localized gastrointestinal stromal tumors. Clin Cancer Res 2004, 10:3076-3081.

22. Wardelmann E, Losen I, Hans V, Neidt I, Speidel N, Bierhoff E, Heinicke T, Pietsch T, Büttner R, Merkelbach-Bruse S: Deletion of Trp-557 and Lys-558 in the juxtamembrane domain of the c-kit protooncogene is associated with metastatic behavior of gastrointestinal stromal tumors. Int $\mathrm{J}$ Cancer 2003, 106:887-895.

23. Andersson J, Bümming $P$, Meis-Kindblom JM, Sihto $H$, Nupponen $N$, Joensuu H, Odén A, Gustavsson B, Kindblom LG, Nilsson B: Gastrointestinal stromal tumors with KIT exon 11 deletions are associated with poor prognosis. Gastroenterology 2006, 130:1573-1581.

24. Dematteo RP, Gold JS, Saran L, Gönen M, Liau KH, Maki RG, Singer S, Besmer P, Brennan MF, Antonescu CR: Tumor mitotic rate, size, and location independently predict recurrence after resection of primary gastrointestinal stromal tumor (GIST). Cancer 2008, 112:608-615.

25. Martín J, Poveda A, Llombart-Bosch A, Ramos R, López-Guerrero JA, García del Muro J, Maurel J, Calabuig S, Gutierrez A, González de Sande JL, Martínez J, De Juan A, Laínez N, Losa F, Alija V, Escudero P, Casado A, García P, Blanco R, Buesa JM, Spanish Group for Sarcoma Research: Deletions affecting codons 557-558 of the C-KIT gene indicate a poor prognosis in patients with completely resected gastrointestinal stromal tumors: a study by the Spanish Group for Sarcoma Research (GEIS). J Clin Oncol 2005, 23:6190-6198.

26. Martin-Broto J, Gutierrez A, Garcia-del-Muro X, Lopez-Guerrero JA, MartinezTrufero J, de Sande LM, Lainez N, Maurel J, De Juan A, Losa F, Andres R, Casado A, Tejido PG, Blanco R, Carles J, Bellmunt J, Gomez-Espana A, Ramos R, Martinez-Serra J, Llombart-Bosch A, Poveda A: Prognostic time dependence of deletions affecting codons 557 and/or 558 of KIT gene for relapse-free survival (RFS) in localized GIST: a Spanish Group for Sarcoma Research (GEIS) Study. Annals of Oncol 2010, 21:1552-1557.

27. Jerzy Lasota, Agnieszka Dansonka-Mieszkowska, Sobin Leslie H, Markku Miettinen: A great majority of GISTs with PDGFRA mutations represent gastric tumors of low or no malignant potential. Lab Invest 2004, 84:874-883.

28. Jerzy Lasota, Jerzy Stachura, Markku Miettinen: GISTs with PDGFRA exon 14 mutations represent subset of clinically favorable gastric tumors with epithelioid morphology. Lab Invest 2006, 86:94-100.

29. van Oosterom AT, Judson I, Verweij J, Stroobants S, Donato di Paola E, Dimitrijevic S, Martens M, Webb A, Sciot R, Van Glabbeke M, Silberman S, Nielsen OS, European Organisation for Research and Treatment of Cancer
Soft Tissue and Bone Sarcoma Group: For the European Organisation for Research and Treatment of Cancer Soft Tissue and Bone Sarcoma Group: Safety and efficacy of imatinib (STI571) in metastatic gastrointestinal stromal tumours - A phase I study. Lancet 2001, 358:1421-1423

30. Demetri GD, von Mehren M, Blanke CD, Van den Abbeele AD, Eisenberg B Roberts PJ, Heinrich MC, Tuveson DA, Singer S, Janicek M, Fletcher JA, Silverman SG, Silberman SL, Capdeville R, Kiese B, Peng B, Dimitrijevic S, Druker BJ, Corless C, Fletcher CD, Joensuu H: Efficacy and safety of imatinib mesylate in advanced gastrointestinal stromal tumors. N Engl J Med 2002, 347:472-480.

31. Verweij J, van Oosterom A, Blay JY, Judson I, Rodenhuis S, van der Graaf W, Radford J, Le Cesne A, Hogendoorn PC, di Paola ED, Brown M, Nielsen OS: Imatinib mesylate (STI-571 Glivec, Gleevec) is an active agent for gastrointestinal stromal tumours, but does not yield responses in other soft-tissue sarcomas that are unselected for a molecular target: Results from an EORTC Soft Tissue and Bone Sarcoma Group phase II study. Eur J Cancer 2003, 39:2006-2011.

32. Debiec-Rychter M, Dumez H, Judson I, Wasag B, Verweij J, Brown M, Dimitrijevic S, Sciot R, Stul M, Vranck H, Scurr M, Hagemeijer A, van Glabbeke M, van Oosterom AT: Use of c-KIT/PDGFRA mutational analysis to predict the clinical response to imatinib in patients with advanced gastrointestinal stromal tumours entered on phase I and II studies of the EORTC Soft Tissue and Bone Sarcoma Group. Eur J Cancer 2004, 40:689-695.

33. Debiec-Rychter M, Sciot R, Le Cesne A, Schlemmer M, Hohenberger $P$, van Oosterom AT, Blay JY, Leyvraz S, Stul M, Casali PG, Zalcberg J, Verweij J, Van Glabbeke M, Hagemeijer A, Judson I, EORTC Soft Tissue and Bone Sarcoma Group; Italian Sarcoma Group; Australasian Gastrolntestinal Trials Group: KIT mutations and dose selection for imatinib in patients with advanced gastrointestinal stromal tumors. Eur J Cancer 2006, 42:1093-1103.

34. Heinrich MC, Owzar K, Corless CL, Hollis D, Borden EC, Fletcher CD, Ryan CW, von Mehren M, Blanke CD, Rankin C, Benjamin RS, Bramwell VH, Demetri GD, Bertagnolli MM, Fletcher JA: Correlation of kinase genotype and clinical outcome in the North American Intergroup Phase III Trial of imatinib mesylate for treatment of advanced gastrointestinal stromal tumor: CALGB 150105 Study by Cancer and Leukemia Group B and Southwest Oncology Group. J Clin Oncol 2008, 26:5360-5367.

35. Van Glabbeke MM, Owzar K, Rankin C, Simes J, Crowley J, GIST Metaanalysis Group (MetaGIST): Comparison of two doses of imatinib for the treatment of unresectable or metastatic gastrointestinal stromal tumors (GIST): A meta-analyis based on 1,640 patients (pts). Proceedings of The American Society of Clinical Oncology abstr 2007, abstr 10004.

36. Blanke CD, Rankin C, Demetri GD, Ryan CW, von Mehren M, Benjamin RS, Raymond AK, Bramwell VH, Baker LH, Maki RG, Tanaka M, Hecht JR, Heinrich MC, Fletcher CD, Crowley JJ, Borden EC: Phase III randomized, intergroup trial assessing imatinib mesylate at two dose levels in patients with unresectable or metastatic gastrointestinal stromal tumors expressing the kit receptor tyrosine kinase: S0033. J Clin Oncol 2008, 26:626-632.

37. Dematteo RP, Ballman KV, Antonescu CR, Maki RG, Pisters PW, Demetri GD, Blackstein ME, Blanke CD, von Mehren M, Brennan MF, Patel S, McCarter MD, Polikoff JA, Tan BR, Owzar K, American College of Surgeons Oncology Group (ACOSOG) Intergroup Adjuvant GIST Study Team: Adjuvant imatinib mesylate after resection of localized, primary gastrointestinal stromal tumor: a randomized, double-blind, placebocontrolled trial. Lancet 2009, 28:1097-1104.

38. Corless CL, Ballman KV, Antonescu C, Blanke CD, Blackstein ME, Demetri GD, von Mehren M, Maki RG, Pisters PW, DeMatteo RP: Relation of tumor pathologic and molecular features to outcome after surgical resection of localized primary gastrointestinal stromal tumor (GIST): Results of the intergroup phase III trial ACOSOG Z9001. Proceedings of The American Society of Clinical Oncology (ASCO) Annual Meeting: June 4-8 2010; Chicago, IL. J Clin Oncol 2010, 28:15s, [abstract 1006].

39. Fletcher JA, Corless CL, Dimitrijevic S, Von Mehren M, Eisenberg B, Joensuu H, Fletcher CDM, Blanke C, Demetri GD, Heinrich MC: Mechanisms of resistance to imatinib mesylate (IM) in advanced gastroinestinal stromal tumor (GIST). Proceedings of The American Society of Clinical Oncology (ASCO) Annual Meeting: May 31 - June 3 2003; Chicago, IL. Edited by Proc Am Soc Clin Oncol 2003, 22, [abstr 3275].

40. Chen LL, Trent JC, Wu EF, Fuller GN, Ramdas L, Zhang W, Raymond AK, Prieto VG, Oyedeji CO, Hunt KK, Pollock RE, Feig BW, Hayes KJ, Choi H, 
Macapinlac HA, Hittelman W, Velasco MA, Patel S, Burgess MA, Benjamin RS, Frazier ML: A missense mutation in KIT kinase domain 1 correlates with imatinib resistance in gastrointestinal stromal tumors. Cancer Res 2004, 64:5913-5919.

41. Tamborini E, Gabanti E, Lagonigro MS, Negri T, Pilotti S, Pierotti MA, Pricl S: KIT/Nal654Ala receptor detected in one imatinib-resistant GIST patient. Cancer Res 2005, 65:1115.

42. Bertucci F, Goncalves A, Monges G, Madroszyk A, Guiramand J, Moutardier V, Noguchi T, Dubreuil P, Sobol H: Acquired resistance to imatinib and secondary KIT exon 13 mutation in gastrointestinal stromal tumour. Oncol Rep 2006, 16:97-101.

43. Wakai T, Kanda T, Hirota S, Ohashi A, Shirai Y, Hatakeyama K: Late resistance to imatinib therapy in a metastatic gastrointestinal stromal tumour is associated with a second KIT mutation. Br J Cancer 2004, 90:2059-2061.

44. Tamborini E, Bonadiman L, Greco A, Albertini V, Negri T, Gronchi A, Bertulli R, Colecchia M, Casali PG, Pierotti MA, Pilotti S: A new mutation in the KIT ATP pocket causes acquired resistance to imatinib in a gastrointestinal stromal tumor patient. Gastroenterology 2004, 127:294-299.

45. Debiec-Rychter M, Cools J, Dumez H, Sciot R, Stul M, Mentens N, Vranckx H, Wasag B, Prenen H, Roesel J, Hagemeijer A, Van Oosterom A, Marynen P: Mechanisms of resistance to imatinib mesylate in gastrointestinal stromal tumors and activity of the PKC412 inhibitor against imatinibresistant mutants. Gastroenterology 2005, 128:270-279.

46. Antonescu CR, Besmer P, Guo T, Arkun K, Hom G, Koryotowski B, Leversha MA, Jeffrey PD, Desantis D, Singer S, Brennan MF, Maki RG, DeMatteo RP: Acquired resistance to imatinib in gastrointestinal stromal tumors occurs through secondary gene mutation. Clin Cancer Res 2005, 11:4182-4190.

47. Liegl B, Kepten I, Le C, Zhu M, Demetri GD, Heinrich MC, Fletcher CD, Corless CL, Fletcher JA: Heterogeneity of kinase inhibitor resistance mechanisms in GIST. J Pathol 2008, 216:64-74.

48. Heinrich $M C$, Corless $C L$, Blanke $C D$, Demetri $G D$, Joensuu $H$, Roberts PJ, Eisenberg BL, von Mehren M, Fletcher CD, Sandau K, McDougall K, Ou WB, Chen $\mathrm{CJ}$, Fletcher JA: Molecular correlates of imatinib resistance in gastrointestinal stromal tumors. J Clin Oncol 2006, 24:4764-4774.

49. Al-Batran SE, Hartmann JT, Heidel F, Stoehlmacher J, Wardelmann E, Dechow C, Düx M, Izbicki JR, Kraus T, Fischer T, Jäger E: Focal progression in patients with gastrointestinal stromal tumors after initial response to imatinib mesylate: a three-center-based study of 38 patients. Gastric Cancer 2007, 10:145-152.

50. Gramza AW, Corless CL, Heinrich MC: Resistance to Tyrosine Kinase Inhibitors in Gastrointestinal Stromal Tumors. Clin Cancer Res 2009, 15:7510-7518

51. Böhmer FD, Karagyozov L, Uecker A, Serve H, Botzki A, Mahboobi S, Dove S: A single aminoacid exchange inverts susceptibility of related receptor tyrosine kinases for the ATP site inhibitor STI-571. J Biol Chem 2003, 278:5148-5155.

52. Demetri GD, Wang Y, Wehrle E, Racine A, Nikolova Z, Blanke CD, Joensuu H, von Mehren M: Correlation of imatinib plasma levels with clinical benefit in patients (Pts) with unresectable/metastatic gastrointestinal stromal tumors (GIST). Proceedings of The 2008 Gastrointestinal Cancer Symposium: January 25-27 2008; Orlando, FL, [abstract 3].

53. Corless CL, Schroeder A, Griffith D, Town A, McGreevey L, Harrell P, Shiraga S, Bainbridge T, Morich J, Heinrich MC: PDGFRA mutations in gastrointestinal stromal tumors: frequency, spectrum and in vitro sensitivity to imatinib. J Clin Oncol 2005, 23:5357-5364.

54. Tamborini E, Pricl S, Negri T, Lagonigro MS, Miselli F, Greco A, Gronchi A, Casali PG, Ferrone M, Fermeglia M, Carbone A, Pierotti MA, Pilotti S: Functional analyses and molecular modeling of two c-KIT mutations responsible for imatinib secondary resistance in GIST patients. Oncogene 2006, 25:6140-6146.

55. Dei Tos AP, Rossi S, Messerini L, Bearzi I, Mazzoleni G, Capella C, Arrigoni G, Sonzogni A, Amore P, Casali PG: The natural history of imatinib-naive GIST: A retrospective analysis of 929 cases with long-term follow-up. Proceedings of The American Society of Clinical Oncology (ASCO) Annual Meeting: May 29 - June 2 2009; Orlando, FL. J Clin Oncol 2010, 27:15s, [abstract 10555].

doi:10.1186/1479-5876-9-75

Cite this article as: Maleddu et al:: The role of mutational analysis of KIT and PDGFRA in gastrointestinal stromal tumors in a clinical setting. Journal of Translational Medicine 2011 9:75.

\section{Submit your next manuscript to BioMed Central and take full advantage of:}

- Convenient online submission

- Thorough peer review

- No space constraints or color figure charges

- Immediate publication on acceptance

- Inclusion in PubMed, CAS, Scopus and Google Scholar

- Research which is freely available for redistribution

Submit your manuscript at www.biomedcentral.com/submit
Biomed Central 